\title{
The role of oncogenic infectious agents in causing liver, stomach, urinary bladder, head and neck and cervical cancers
}

\author{
Abstract \\ Background: Understanding the pathogenesis and predisposing factors for cancer is a \\ major concern. Several studies have elucidated the role of infection in developing certain \\ malignancies.
}

Aim: The aim of this work was to assess the role of infectious agents in causing liver, stomach, urinary bladder, head and neck and cervical cancers.

Methods: This case-control study included 181, diagnosis of several infectious agents included genetic and serological tests in both groups. The relative risk of each infectious agent was then calculated.

Results: Oncogenic infectious agents cause $81.2 \%$ of studied cancers. HCV was detected in $92.2 \%$ of $\mathrm{HCC}$ with a relative risk of 4.6 , HBV was detected in $5 \%$ of cases and relative risk of 4.8 , H. pylori DNA was found in $77 \%$ of gastric cancer and a relative risk of 1.2 and $\mathrm{S}$. heamatobium was found in $37.5 \%$ of urinary bladder cases with a relative risk of 31 . Finally, HPV16 DNA was detected in $56.2 \%$ of head and neck cancer and $66.6 \%$ of cervical cancer with a relative risk of 3.12 and 3.7 respectively.

Conclusion: Infections play an important role in the pathogenesis of cancer. Better attention to Infection prevention and control programs must be adapted to decrease the burden of malignant diseases.
Volume 3 Issue 2 - 2016

\author{
Reham Mohamed El shabrawy,' Randa \\ Saddek Abdelateef, ${ }^{2}$ Ahmed Abdel Reheem Al \\ Nagar, ${ }^{3}$ Amira Amin Salem ${ }^{4}$ \\ 'Lecturer of Medical Microbiology and Immunology, Faculty of \\ Medicine, Zagazig University, Egypt \\ ${ }^{2}$ Assistant professor of Medical Microbiology and Immunology. \\ Faculty of Medicine, Zagazig University, Egypt 3Lecturer of \\ Medical Oncology, Faculty of Medicine, Zagazig University, Egypt \\ ${ }^{3}$ Lecturer of Medical Oncology, Faculty of Medicine, Zagazig \\ University, Egypt \\ ${ }^{4}$ Lecturer of Pathology, Faculty of Medicine, Zagazig University, \\ Egypt
}

Correspondence: Reham Mohamed El Shabrawy, Designation Lecturer of Medical microbiology and Immunology, Faculty of Medicine, Zagazig University, Attia Al Khamry Street, Al Kawmia, Al Sharkia, Zagazig Egypt, Tel 201005275672

Email rehman_elshabrawy@yahoo.com

Received: April 01, 2016 | Published: April 05, 2016

Keywords: Cancer, Infectious diseases, Relative risk, HCV

Abbreviations: HBV, Hepatitis B Virus; HPV, Human Papilloma Virus; HCV, Hepatitis C Virus; EBV, Epstein-Barr Virus; HIV 1, Human Immunodeficiency Virus Type 1; HTLV 1, Human T-Cell Lymphotropic Virus Type I; HBsAg, Hepatitis B Surface Antigen; HCC, Hepatocellular Carcinoma; WHO, World Health Organization

\section{Introduction}

Cancer is currently a growing problem worldwide. In Egypt, the crude incidence rate on the national level for all sites, excluding non-melanoma skin cancer was 113.1/100,000 for both sexes. As the population of Egypt is expected to increase steadily, consequently, the number of cancer cases will increase due to both population growth and demographic change due to ageing of the population.

Several epidemiological, clinical and biological studies have provided sufficient evidences that several infectious agents are known causes of cancer. These human carcinogens include: hepatitis B virus (HBV), hepatitis C virus (HCV), certain strains of the human papilloma virus (HPV), Helicobacter pylori, Epstein-Barr virus (EBV), human immunodeficiency virus type 1 (HIV 1), human T-cell lymphotropic virus type I (HTLV 1), Kaposi's sarcoma herpesvirus (HHV8) and the parasite Schistosoma. ${ }^{2-4}$ The aim of this study is to assess the burden of infection in causing solid cancers in cases presented to medical oncology department, Zagazig University Hospitals, Egypt.

\section{Methodology}

This is a case-control study, done in Medical Oncology and Medical Microbiology and Immunology departments, Faculty of medicine, Zagazig University, Egypt. Zagazig university hospitals are regional tertiary hospital that serves more than six governors providing service to a population of more than nine million people living in the east of Egypt.

Control group: number and characters of control group were selected to adapt with age and sex for each cancer group.

Cases: Patients included in this study attended Medical Oncology department for the period of June 2013 to June 2015 and were diagnosed as having cancer clinically and laboratory.

Inclusion criteria: Patients suffering from solid tumors where association with oncogenic infectious agent were suspected HCC, Urinary bladder cancer, Gastric carcinoma, Head and neck and cancer cervix

Exclusion criteria: Patient suffering from hematological malignancies, breast and colon cancer, ovarian cancers and uterine cancers.

Further investigations were done to identify the causing infectious agent, if present. These investigations include:

\section{Diagnosis of $\mathrm{H}$. pylori}

In control group: H. pyloriAg was detected in stool of 50 apparently healthy individuals using ELISA kit (International ImmunoDiagnostics MICROWELL) according to manufactures guidelines.

Patient group: $H$. pyloriwas detected in cancer tissue obtained during upper GIT endoscope using PCR. DNA was extracted using (Qiagn) extraction kit from tissue. The following primers were used F' AAG CTT TTA GGG GTG TTA GGG GTT T, R' AAG CTT ACT TTC TAA CAC TAA CGC giving a product of $294 \mathrm{bp}$. Reactions were performed in a 50-ml volume using thermofisher master mix, $2 \mathrm{ul}$ of 
each primer, $5 \mathrm{ul}$ of extracted DNA, elongation step was done at $72^{\circ} \mathrm{C}$ were used. $2 \%$ agarose gel was used to detect the PCR product. ${ }^{5}$

\section{Diagnosis of HCV}

Control group: Diagnosis depends on detecting viral $\mathrm{Ab}$ in serum of 100 apparently healthy individuals using Anti HCV ELISA kit (Prechek Bio, Inc, USA)

Cases were diagnosed using HCV real time PCR: Viral RNA was extracted using (Thermoscientific, USA) lysis solution. Amplification was done using TaqMan probe. The Specific Mastermix contains reagents and enzymes for the specific amplification of HCV and for the direct detection of the specific amplicon in fluorescence channel Cycling A. FAM of amp icon, and HEX for the internal control using Strategen Mx Pro- Mx3005P. Simply, $15 \mu$ l of the Master Mix was pipetted into each labelled PCR tube. Then $10 \mu$ of extracted RNA was added to each sample tube and mixed well by pipetting up and down. Correspondingly, Close the PCR tubes and transfer the same into the plate of the Strategen Mx Pro- Mx3005PTM instrument Quality Control: One negative control (10 $\mu$ l of Water, PCR grade) was included per PCR run. In addition to one external positive control standards $(10 \mu \mathrm{l}$ of the Standards).Amplification was performed first at $45 \mathrm{C}$ for $10 \mathrm{~min}$ and for 45 cycles at $95 \mathrm{C}$ for $5 \mathrm{~s}$ and $60 \mathrm{C}$ for $30 \mathrm{~s}$, and $25 \mathrm{C}$ for $1 \mathrm{~min}$ in Strategen Mx Pro- Mx3005PTM instrument.

\section{Diagnosis of $\mathrm{HBV}$ :}

Control group: Hepatitis B Surface Antigen (HBsAg) was detected using ELISA Kit in the serum of 100 apparently healthy individuals.

Patient group: Diagnosis was based on real time PCR. Viral RNA was extracted using (Thermoscientific, USA) lysis solution. Realtime PCR was performed in a $50 \mu \mathrm{l}$ reaction mixture containing $25 \mu \mathrm{l}$ TaqMan Universal PCR master mix (Applied Biosystems) with $0.2 \mu \mathrm{l}$ primers, $0.1 \mu \mathrm{l}$ probes, and $10 \mu \mathrm{l}$ extracted DNA. 50 cycles of $95^{\circ} \mathrm{C}$ for $15 \mathrm{~s}$ and $60^{\circ} \mathrm{C}$ for $1 \mathrm{~min}$ were performed with an (Stratgen realtime PCR detectionsystem). Internal and external control was used.

\section{Diagnosis of HPV:}

In control group: Detection of using Anti HPV16 antibody in the serum of 50 individuals in the control groups (Abcam, UK)

Diagnosis of HPV by PCR form the tumor mass: DNA was extracted from frozen tumor tissue, (according to Herbst et al., 1990) $15 \mathrm{mM} \mathrm{MgCl} 2$ (buffer $1 \times$ ), $800 \mu \mathrm{M}$ of dNTPs, $50 \mathrm{pmol} /$ $\mu 1$ of each oligonucleotide primer, 1.25 U from Hot Star TaqDNA polymerase (Invitrogen) 40 cycles: $94^{\circ} \mathrm{C} / 45 \mathrm{sec} 55^{\circ} \mathrm{C} / 45 \mathrm{sec} 72^{\circ} \mathrm{C} / 45$ sec 1 cycle: $72^{\circ} \mathrm{C} / 5$ min using the following pairs of primers that amplify 450pb. ${ }^{6}$ F' 5'CGTCCMARRGGAWACTGATC3', R' 5'GCMCAGGGWCATAAYAATGG3'2\% agarose gel was used to detect the PCR product

\section{Diagnosis of Schistosoma}

Control group: Diagnosis depends on detection of Schistosoma heamatopium egg in urine in 50 healthy individuals.

Cases: Schistosmal DNA was detected from tumor tissue obtained during cystoscope Extraction o the parasite DNA was done using (Qiagen). The PCR was carried out using the following primers (forward: 5'-GATCTCACCTATCAGACGAAAC-3' and reverse: $5^{\prime}$-TCACAACGATACGACCAAC-3'), in $20 \mu$ reaction volume containing $10 \mu \mathrm{L}$ master mix (Fermantas, UK), $1 \mu \mathrm{M}$ of each of the amplification primers and $5 \mu \mathrm{L}$ of template DNA. Using the following protocol: denaturing step of $15 \mathrm{~min}$ at $95^{\circ} \mathrm{C}$, followed by 33 cycles of $95^{\circ} \mathrm{C}$ for $30 \mathrm{sec}$, annealing temperature of $53^{\circ} \mathrm{C}$ for $1.5 \mathrm{~min}$, and expansion at $72^{\circ} \mathrm{C}$ for $1 \mathrm{~min}$, followed by a final extension step at $60^{\circ} \mathrm{C}$ for $5 \mathrm{~min}$. The products were examined on a $2 \%$ agarose gel stained with ethidium bromide $(10 \mathrm{mg} / \mu \mathrm{L})$ and visualized with $\mathrm{UV}$ light. The size marker $100 \mathrm{bp}$ ladder was used to estimate band size of $121 \mathrm{bp} .^{7}$

Statistical analysis: Statistical analysis was performed using the Statistical Package for the Social Sciences for Windows (version 17.0; SPSS, Chicago, IL, USA). Data were expressed using descriptive statistic (mean \pm standard deviation) and were analyzed using Chisquare. One-way analysis of variance (ANOVA) test was done to compare different parameters between more than two groups. Relative risk was calculated to determine the risk of each infectious disease.

\section{Results}

During the period of the study from June 2013 to June 2015, 926 patients suffering from cancer attended Medical Oncology Department, Faculty of Medicine, Zagazig University, of those, 181 cases suffering from liver cancer, urinary bladder cancer, gastric cancer, head and neck cancer and cervical carcinoma figure 1-2 and figure 3.

According to our results, 147 cases were associated with oncogenic infectious agents, this represent $(15.8 \%)$ of all cancer cases (926) and $(81.2 \%)$ of cases included in the study (181). The most common cases were presented with HCC (95 patients), followed by gastric cancer then urinary bladder cancer. Age range, mean and standard deviation were calculated; analysis of variance showed that there is no significant difference regarding age in different types of cancer $\mathrm{P}$ $>0.05$ (Table 1).

The total number of males presented with cancers associated with oncogenic infectious was $114(77.5 \%)$. HCC was the first cause of cancer in males 81 cases followed by Gastric cancer 14 cases. While, The total number of Females presented with cancers associated with oncogenic infectious was $33(22.4 \%)$, HCC was the first cause of cancer in females 14 cases followed by cervical cancer 8 cases, Number and percentage of distribution of different tumours in male and female are shown in Table 1 and Table 2.

When we evaluated infection as a risk factor for causing cancer, we found that studied infectious agents significantly increase the risk of cancer Relative risk (RR) is $>1$ with $\mathrm{P}$-value $>0.05$ except $\mathrm{H}$. pylori and HBV which although having RR of 1.2 and 4.8 respectively, the calculated P-values were $>0.05$ as described in Table 3 and figure 2. Both HBV and HCV exert risk. Of the 95 cases associated with hepatitis viruses, 95 were infected with $\mathrm{HCV}$, of these cases 5 were co-infected with both types of viruses.

\section{Discussion}

According to our results, Cancers associated with (HCV, HBV, $\mathrm{HPV}$ and $\mathrm{H}$. pylori and S. heamatopium) infections represent $15.8 \%$ of all cancer cases presented to Medical oncology department, Faculty of Medicine, Zagazig University. Where HCV, HBV and HPV viruses and S. heamatobium, H. pylori cause 181 cases. This incidence is accepted in view of the fact that Infection with human oncogenic viruses is the cause of $\square 10.8 \%$ of human cancers worldwide. ${ }^{8}$

Hepatocellular carcinoma (HCC) is the fifth most common cancer and third most common cause of cancer related mortality worldwide. ${ }^{8}$ According to this study, both $\mathrm{HCV}$ and $\mathrm{HBV}$ increase the risk of HCC more than four times. Both viruses, however, are known cause of chronic liver infections, which lead to liver cirrhosis and liver cancer $^{9-11}$ 
Table I Patients included in the study ad frequency of different types of cancers

\begin{tabular}{|c|c|c|c|c|c|}
\hline Site of Cancer & Cancers & No/Percentage & Age Range/ Mean士SD & $\mathbf{F}^{*}$ & $\mathbf{P}$ \\
\hline $\mathrm{HCC}$ & 103 & & $(40-75) 58.7 \pm 6.7$ & 1.632 & 0.154 \\
\hline Urinary Bladder & 24 & & (42-7I) $60.6 \pm 9.6$ & & \\
\hline Gastric Cancer & 26 & & $57.1 \pm 9.2$ & & \\
\hline Head and Neck & 16 & & (39-67) $55.7 \pm 9.9$ & & \\
\hline Cervical Cancer & 12 & & (47-62) $54.6 \pm 7.5$ & & \\
\hline Total & 181 & & & & \\
\hline
\end{tabular}

*F: F ratio of ANOVA

Table 2 Frequency of different tumors in Males and Females

\begin{tabular}{|c|c|c|c|c|c|c|}
\hline Site of Cancer & $\begin{array}{l}\text { Total Number of } \\
\text { Cases }\end{array}$ & $\begin{array}{l}\text { Cancers Associated With Infectious } \\
\text { Agents No/Percentage }\end{array}$ & Male & Female & $\mathbf{X} 2$ & $\mathbf{P}$ \\
\hline $\mathrm{HCC}$ & 103 & $95(92.2 \%)$ & 81 (85.2\%) & 14 (14.7\%) & 0.592 & 0.441 \\
\hline Urinary Bladder & 24 & $15(62.5 \%)$ & $12(80 \%)$ & $3(20 \%)$ & 0.533 & 0.465 \\
\hline Gastric Cancer & 26 & $20(77 \%)$ & 14 (70\%) & $6(30 \%)$ & 2.621 & 0.105 \\
\hline Head and Neck & 16 & $9 \quad(56.6 \%)$ & $7(77.7 \%)$ & $2(22.2 \%)$ & 0.78 & 0.377 \\
\hline Cervical Cancer & 12 & $(66.6 \%)$ & ------ & 8 & ---- & ---- \\
\hline Total & 181 & 147 (8I.2\%) & I I 4 (77.5\%) & $33(22.4 \%)$ & & \\
\hline
\end{tabular}

Table 3 Risk factor for different infectious agents

\begin{tabular}{|c|c|c|c|c|c|}
\hline Infectious Agents & Site of Cancer/No & Case (No \%) & Control (No \%) & Relative Risk/ Cl' & P-Value \\
\hline $\mathrm{HCV}$ & $\mathrm{HCC}$ & 95 (92.2\%) & $20(20 \%)$ & $4.6(3.1-6.8)$ & $<0.0001$ \\
\hline HBV & $\mathrm{HCC}$ & $5(5 \%)$ & $2(2 \%)$ & $4.8(0.57$ to 40.4$)$ & 0.148 \\
\hline H. pylori & Gastric Cancer & $20(77 \%)$ & $31(62 \%)$ & I.2(0.9I-I.6) & 0.621 \\
\hline S. heamatobium & Urinary Bladder & $9(37.5 \%)$ & I (2\%) & $31(4.38-222.4)$ & 0.0006 \\
\hline HPV & Head and Neck & $9(56.2 \%)$ & $9(18 \%)$ & $3.1(1.5-6.5)$ & 0.0023 \\
\hline HPV & Cervix & $8(66.6 \%)$ & $9(18 \%)$ & $3.7(1.8-7.56)$ & 0.0003 \\
\hline
\end{tabular}

'Cl: Confidence Interval

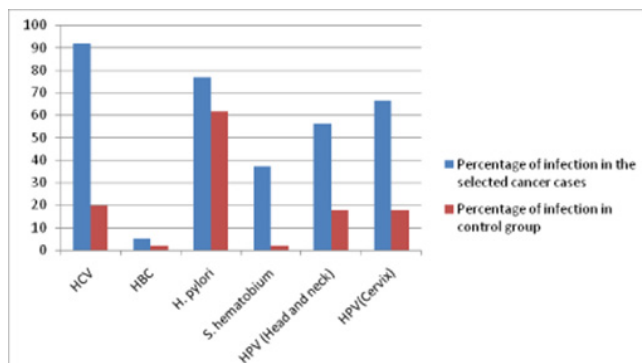

Figure I Relative Risk for different infectious agents.

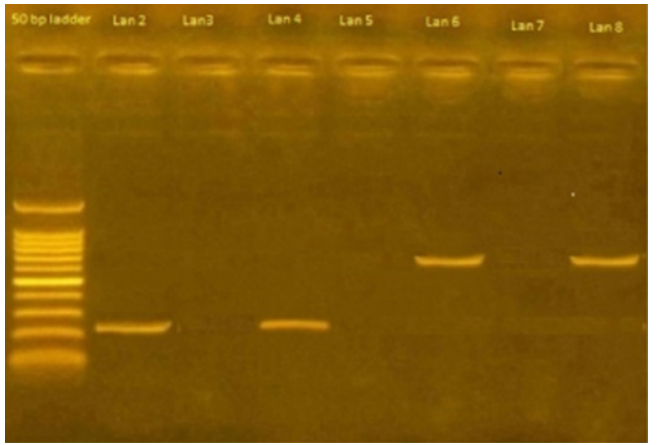

Figure 2 Agarose gel electrophoresis of HPV and S. heamatopium detection bands.

Lan I: Shows 50 bp ladder.

Lan2 and 4: Shows I20bp of S. heamatobium.

Lan 6 and 8: Shows 450 bp of HPV.

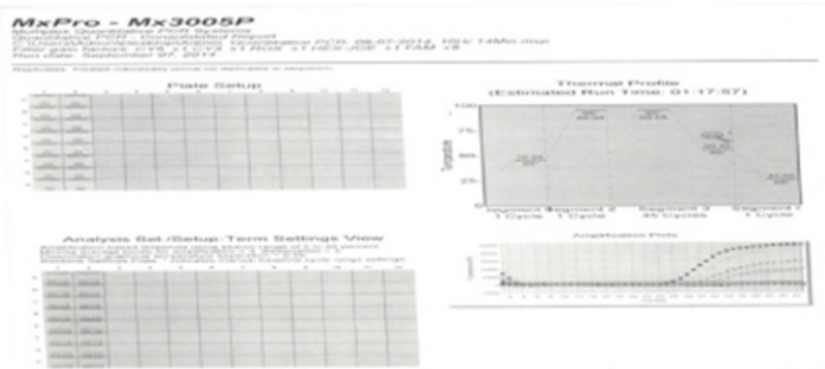

Figure 3 Risk factor for different infectious agents.

The World Health Organization (WHO) estimated that worldwide, 240 million people are chronically infected with hepatitis B (WHO 2015), while 130-150 million people globally have chronic hepatitis $C$ infection. ${ }^{11,12}$ According to our results, Hepatoma is the most common solid tumor. This finding is consistent with other findings in many Egyptian regional registries liver cancer is reported to be the first cancer in men and the second in women. In Gharbiah populationbased cancer registry, liver cancer represents $12.7 \%$ of male cancers and $3.4 \%$ of female cancers. ${ }^{1,12}$ The relative high incidence of liver cell cancer in Egypt in our study and other studies reflects the high prevalence of viral hepatitis in Egypt. ${ }^{13}$ These results are also supported by reports from other places of the world. In Ghana, for example, HCC is considered to be the first cause of cancer mortality. ${ }^{14}$ Worldwide HBV is more accused to cause HCC than HCV, however this is not the case in this study and other studies in Egypt, as HCV incidence is highly variable among different geographic locations. ${ }^{15}$ 
The Egyptian Ministry of Health estimated that the incidence of HCV infection among Egyptians is $10-15 \%$ of Egyptian population and about $2 \%$ are chronically infected with HBV. ${ }^{16}$ In this study the RR of HCV to cause HCC was 4.6 with highly significant $\mathrm{p}$ value $<0.05$, regarding HBV, the RR was 4.8 , however, the $\mathrm{p}$ value was not significant, this can be explained by small sample size.

World health organization considered Schistosoma as being carcinogenic to human. ${ }^{17}$ In Egypt, bladder cancer accounts for $17 \%$ of all cancers in males and 5\% in females. Carcinogenic mechanism may include either direct election of excessive inflammatory molecule caused by the parasite itself or the parasite may permit co-infection by other viruses or bacteria. Other factors like tobacco smoking and nitrosamines intake may also play a role. ${ }^{18}$

In the current study, Urinary bladder cancer is the second most commonly occurring cancers in Males after HCC. Schistosoma heamatobium were detected in 9 cases with a RR of 31 . It should be noted that prevalence of the parasite has markedly decreased from $70-80 \%$ in 1920 to $1.2 \%$ due to the successful mass treatment which was also accompanied by aggressive public awareness campaigns. ${ }^{19,20}$

HPV is associated with several forms of cancers, oropharyngeal tumors and cervical tumors are of special interest due to increased incidence of these cancers worldwide. ${ }^{21-23}$ According to our results 12 cases were diagnosed as cervical carcinoma. HPV16 infects $18 \%$ of the females in the control group and was detected in $66.6 \%$ of cervical cancer cases representing About four times higher risk for developing cancer in females In Egypt, current estimates indicate that every year, 514 women are diagnosed with cervical cancer and 299 die from the disease. Most cases of cervical carcinoma are due to HPV16. ${ }^{24}$

Worldwide, Cervical cancer is the second most common malignancy in women, over 466,000 new cases of cervical cancer are diagnosed and 231,000 women die from this type of cancer each year. High risk HPV is the major cause of $80 \%$ of this cancer. ${ }^{25}$ Rueusser and colleague found that $99 \%$ of cancer cervix is attributed to HPV infection where HPV16 is the most prevalent genotype. ${ }^{26}$

The role of High risk HPV subtypes in causing cancer cervix was the main activator for applying screening programs and vaccination to adolescent girls. Which have significantly reduced the rates of cancer cervix over the past 50 years. ${ }^{27}$ Unfortunately, these strategies are not applied in Egypt till now. According to our results 26 cases were diagnosed as Head and neck carcinoma. Nine (56.2\%) of them were associated with HPV16 infection. HPV doubled the risk of occurrence of head and neck cancer. The incidence of oropharyngeal SCC is increasing worldwide depending on the data obtained from reports from United States and Europe. ${ }^{28}$

In Egypt, Gastric carcinoma is the $12^{\text {th }}-14^{\text {th }}$ most common cancer. H. pylori is considered carcinogenic bacteria that has been involved in the process of gastric abnormal growth and metaplasia. ${ }^{29-34}$ According to the results of this study, H. pylori was detected in 62 $\%$ of control patients and in $77 \%$ of cases, calculated RR was 1.2 , However, $\mathrm{P}$ value $=0.621$ was no significant. These results can be explained by the high prevalence of the bacteria in the Egyptian population and so further studies with larger number of patients may be needed to accurately determine the role of the bacterium in causing gastric cancer in Egyptian population.

\section{Conclusion}

Infections play an important role in the occurrence of cancer, more effort and more resources must be allocated to screen, prevent and treat carcinogenic infections.

\section{Acknowledgments}

None.

\section{Conflicts of interest}

None.

\section{References}

1. Ibrahim AS, Khaled HM, Mikhail NN, et al. Cancer Incidence in Egypt: Results of the National Population-Based Cancer Registry Program. $J$ Cancer Epidemiol. 2014:437971.

2. Lukaszuk K, Liss J, Wozniak I, et al. Human papillomavirus type 16 status in cervical carcinoma cell DNA assayed by multiplex PCR. J Clin Microbiol. 2003;41(2):608-612.

3. Fu CL, Odegaard JI, Herbert DR, et al. A Novel Mouse Model of Schistosoma haematobium Egg-Induced Immunopathology. PLoS Pathog. 2012;8(3):e1002605.

4. Mueller NE. Cancers Caused by Infections: Unequal Burdens. Cancer Epidemiol Biomarkers Prev. 2003;12(3):237s.

5. Lage AP, Godfroid E, Fauconnier A, et al. Diagnosis of Helicobacter pylori Infection by PCR: Comparison with Other Invasive Techniques and Detection of cagA Gene in Gastric Biopsy Specimens. J Clin Microbiol. 1995;33(10):2752-2756.

6. Venceslau E, Bezerra M, Lopes A, et al. HPV detection using primers MY09/MY11 and GP5+/GP6+ in patients with cytologic and/or colposcopic changes Detecção de HPV utilizando iniciadores MY09/ MY11 e GP5+/GP6+ em pacientes com alterações citológicas e/ou colposcópicas. J Bras Patol Med Lab. 2014;50(4):280-285.

7. Ibironke OA, Phillips AE, Garba A, et al. Diagnosis of Schistosoma haematobium by Detection of Specific DNA Fragments from Filtered Urine Samples. Am J Trop Med Hyg. 2011;84(6):998-1001.

8. Schiffman M, Wentzensen N, Wacholder S, et al. Human Papillomavirus Testing in the Prevention of Cervical Cancer. J Natl Cancer Inst. 2011;103(5):368-383.

9. Ajiro M, Zheng ZM. Oncogenes and RNA splicing of human tumor viruses Emerg Microbes Infect. 2014;3(9):e63.

10. Baran B. Nucleos (t)ide analogs in the prevention of hepatitis B virus related hepatocellular carcinoma World $J$ Hepatol. 2015;7(13):1742-1754.

11. WHO. Hepatitis B. Fact Sheet WHO/204. Geneva, Switzerland. 2015.

12. WHO. Hepatitis C. Fact Sheet WHO/204. Geneva Switzerland.

13. El Attar. Cancer statistics. NCI, Department of Biostatics and Epidemiology, Cairo, Egypt. 2004

14. Aswan D, El-Minia. The National Cancer Registry Program of Egypt (NCRPE). Reports and Statistics, NCRPE. 2005.

15. Mutocheluh M, Kwarteng K. Knowledge and occupational hazards of barbers in the transmission of hepatitis B and C was low in Kumasi, Ghana. Pan Afr Med J. 2015;20:260.

16. Poustchi H, Sepanlou S, Esmaili S, et al. Hepatocellular carcinoma in the world and the middle east. Middle East J Digest Dis. 2010;2(1):31-41.

17. El-Zanaty F, Way A. Egypt demographic and health survey 2008. Ministry of Health and Population Cairo, Egypt. 2008

18. El-Sharkawi F, El Sabah M, Hassan Z, et al. The biochemical value of urinary metalloproteinases 3 and 9 in diagnosis and prognosis of bladder cancer in Egypt. J Biomed Sci. 2014;21:72

19. Honeycutt J, Hammam O, Fu CL, et al. Controversies and challenges in research on urogenital schistosomiasis-associated bladder cancer. Trends Parasitol. 2014;30(7):324-332. 
20. Barakat RM. Epidemiology of Schistosomiasis in Egypt: Travel through Time: Review. J Adv Res. 2013;4(5):425-432.

21. Khaled H. Schistosomiasis and Cancer in Egypt: review. J Adv Res. 2013;4(5):461-466.

22. Betiol J, Villa L, Sichero L. Impact of HPV infection on the development of head and neck cancer. Braz J Med Biol Res. 2013;46(3):217-226.

23. Dunne EF, Park IU. HPV and HPV-associated diseases. Infect Dis Clin N Am. 2013;27(4):765-778.

24. Egawa N, Egawa K, Griffin H, et al. Human Papilloma viruses; EpithelialT ropisms, and the Development of Neoplasia. Viruses. 2015;7(7):3863-3890

25. Ghada EE. ProExC is a novel marker for distinguishing between primary endometrial and endocervical adenocarcinomas Journal of the Egyptian National Cancer Institute. 2013;25(2):87-93.

26. Singh M, Mehrotra S, Kalra N, et al. Correlation of DNA Ploidy with Progression of Cervical Cancer. J Cancer Epidemiol. 2008:298495.

27. Reusser N, Downing C, Guidry J, et al. HPV Carcinomas in Immunocompromised Patients J Clin Med. 2005;4(2):260-281.

28. Al-Kalaawy M, El-Zohairy MA, Mostafa A, et al. Gastrointestinal stromal tumors (GISTs), 10-year experience: Patterns of failure and prognostic factors for survival of 127 patients. J Egypt Natl Canc Inst. 2012;24(1):31-39.
29. Xie X, Piao L, Bullock BN, et al. Targeting HPV16 E6-p300 interaction reactivates p53 and inhibits the tumorigenicity of HPV-positive head and neck squamous cell carcinoma. Oncogene. 2014;33(8):1037-1046.

30. Zeeneldin A, Ramadan H, El Gammal MM, et al. Gastric carcinoma at Tanta Cancer Center: a comparative retrospective clinico-pathological study of the elderly versus the non-elderly. J Egypt Natl Canc Inst. 2014;26(36):127-137.

31. Malfertheiner P, Megraud F, O'Morain CA, et al. Management of Helicobacter pylori infection-the Maastricht IV/ Florence Consensus Report. Gut. 2012;61(5):646-664.

32. Saber MM, Zeeneldin AA, Samra MA, et al. Primary gastrointestinal lymphoma in an Egyptian district: A study using a population-based cancer registry. J Egypt Natl Canc Inst. 2013;25(2):95-101.

33. Yong X, Tang B, Li B, et al. Helicobacter pylori virulence factor CagA promotes tumorigenesis of gastric cancer via multiple signaling pathways. Cell Commun Signal. 2015;13:30.

34. Sugano K, Tack J, Kuipers EJ, et al. Kyoto global consensus report on Helicobacter pylori gastritis Gut. 2015;64(9):1353-1367. 